\title{
Grieving during a pandemic: A psycho-theological response
}

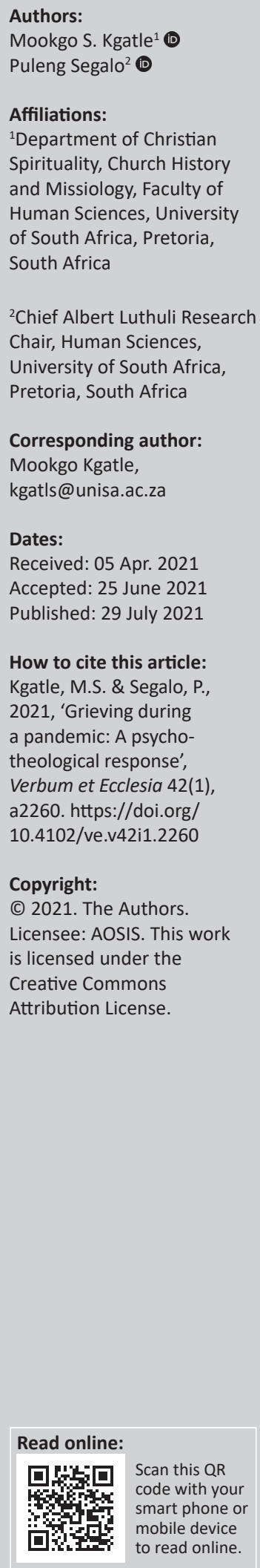

Collective grieving during the death and the burial processes of a loved one forms part of the healing process of many Africans in different contexts. However, with the coronavirus disease 2019 (COVID-19) pandemic and the various restrictions imposed during the hard lockdown, the form and shape of grieving has had to change. Factors such as limitations on the number of people who can attend the funeral, lack of contact with the corpse, overall travel restrictions and shortened funeral services have contributed to how people mourn and grieve together. Using a psycho-theological framework, this article argues for the importance of giving serious consideration to both the psychological and spiritual wellbeing of mourners, specifically in the context of COVID-19. Drawing on an Afrocentric perspective and using a psychological and theological analysis, the article will examine grief, bereavement and mourning, and highlight the ways in which COVID-19 has affected these processes. This analysis will afford us the opportunity to redefine grieving as a psychological and theological response.

Interdisciplinary and/or interdisciplinary implications: This article juxtaposes the theological perspectives with psychological perspectives in analysing the concept of grief during a pandemic. This article suggests communal grieving in contrast to individualised grieving in order to cope with pandemics such as COVID-19.

Keywords: grieving; mourning; psychology; theology; psycho-theological theory; COVID-19.

\section{Introduction}

Africans, much like other human beings, go through various coping mechanisms to deal with the pain of losing their loved ones (Kübler-Ross \& Kessler 2005). Grieving is a necessary healing process for dealing with the loss of loved ones (Kenworthy \& Kirkham 2011; Kessler 2019; Kumar 2005; Kübler-Ross \& Kessler 2005). For healing to occur, it is necessary for the grieving person to be afforded the opportunity to draw on coping mechanisms during death and burial processes, (Kübler-Ross \& Kessler 2005). Healing mechanisms include a journey of finding meaning, which is also essential for helping the grieving person/s to overcome their misery (Kessler 2019).The challenge however is that during a pandemic such as the coronavirus disease 2019 (COVID-19), these coping mechanisms get interrupted. Thereby, hindering the healing process of the grieving person/s. Drawing on both psychological and theological perspectives, this article examines the ways in which the COVID-19 pandemic has affected the grieving for loved ones during death and burial processes. The article will focus specifically on how many African societies cope with death and burial in different contexts; the ways in which coping with bereavement was interrupted by the pandemic; grief as an embodied experience; and, lastly, the importance of taking African burial rituals seriously and acknowledging grief as a collective experience.

\section{Complexities of mourning during COVID-19}

The coronavirus disease 2019 reshaped the processes that people adopt when it comes to mourning. There are numerous activities surrounding the death of a loved one, but restrictions that were imposed as a result of the pandemic affected how these could be actualised. For example, viewing the body of the deceased became a challenge during the pandemic, specifically the body of an individual who died of COVID-19. One of the COVID-19 regulations in South Africa is that the body of the deceased is to be handled by a specific undertaker and wrapped in a bag and labelled as a COVID-19 dead body (Western Cape Government 2020). Although family members are permitted to view the body of the deceased in the mortuary, they are not allowed to touch it. Further restrictions were imposed on people with respiratory symptoms; they were not allowed 
to view the dead body in order to avoid transmission to other people (World Health Organization 2020). The challenge to viewing the dead body should also be understood in the context of the restrictions on the number of people who could attend the funeral. During the hard lockdown in South Africa, this number was limited to 50 people (Du Toit 2020). This limit on the number of people who could be a part of the burial process meant that many did not get the opportunity to pay their last respects. The after-funeral gatherings, such as the after-tears party, were also not permitted during the hard lockdown. After-tears parties are perceived as a form of healing ritual whereby people gather together after the burial of a loved one to reminisce and collectively remember the life of the deceased.

The hosting of the after-tears party is perceived by some as disrespectful (Letsosa 2010; Lukhele 2016; Mhlongo 2007; Semenya 2013), and as part of lavish funerals by others in Africa (Posel 2007; cf. Kotzé, Els \& Rajuili-Masilo 2012). According to Lukhele (2016), the after-tears party is notorious for 'the presence and consumption of alcohol, for feasting, loud music, women in party dress, and generally licentious behaviour'. However, in his doctoral thesis, Setsiba (2012) has argued that if utilised in a proper and respectful manner, the after-tears party can become a hugely useful coping mechanism. This can be accomplished by proceeding with the ritualistic celebrations but without the use of alcohol and dressing in a disrespectful manner that will detract from the dignity of the deceased and the family. According to Kotzé et al. (2012:753), there are many other post-funeral events, such as 'the sharing of possessions with extended family, cleansing rituals, and practices concerning clothes', that are also a part of healing processes in many African contexts. However, the after-tears party remains immediate and, if applied properly, can be useful for mourners.

Another restriction that hindered people from coping with death and burial was the restrictions on the interprovincial travel, especially under alert level 5 of the COVID-19 lockdown in South Africa (Kgatle 2020b; cf. Banerjee et al. 2020). This meant that even those who wanted to be part of the 50 people allowed to attend the funeral were unable to do so hindered by the interprovincial travel ban. Travelling was allowed only if the traveller could prove travelling is for a valid reason, which meant that they had to obtain a permit from the police station (Rogerson \& Rogerson 2020). In order to obtain a permit, the applicants had to brave long queues and produce relevant documents such as the death certificate and supporting documents. All these challenges, coupled with the strain of passing through roadblocks in almost every town during the hard lockdown, discouraged prospective funeral attendees from travelling, prompting them to stay at home.

Moreover, under alert levels 2-5 of the lockdown in South Africa, most of the borders were closed to restrict crossborder travel. At the border between South Africa and Zimbabwe, these restrictions were intensified by erecting a
$40 \mathrm{~km}$ fence to prevent illegal entry into South Africa (Zanker \& Moyo 2020). This closing of the borders was not unique to South Africa. Dodds et al. (2020:292) states: 'Countries have shut their own borders to non-residents and foreign nationals while scrambling to repatriate their own nationals'. In terms of closing the borders into South Africa, under Government Gazette 43189 of 31 March 2020, repatriation was allowed only under very strict conditions.

Repatriation of foreign nationals from South Africa back to their respective countries is allowed, provided the foreign countries charter their aircraft to South Africa without passengers, except for the crew. The crew is not allowed to disembark. ${ }^{1}$ (p. 1)

These conditions meant that individuals could initiate the repatriation of their loved ones, but only at the request of their respective countries, and most importantly at their own cost. This meant that families willing to repatriate the dead bodies of the loved ones could do so only after the easing of the lockdown regulations, and when they could afford to do so. All these restrictions require a proper examination of how grieving can be addressed in the context of COVID-19.

\section{Psycho-theological insights on grieving during COVID-19}

Theories of bereavement, grief and mourning within the discipline of psychology have long promoted the EuroWestern perspective (Kubler-Ross 1969; Kubler-Ross \& Kessler 2005; eds. Stroebe, Stroebe \& Hansson 1993; eds. Sutcliffe, Tufnell \& Cornish 1998) at the expense of African-centred epistemologies. According to Walter (2007), psychology and psychiatry practitioners tend to look at grief as an experience that affects an individual and, as a result, they focus on attending to this as 'individual grief' instead of seeing and acknowledging grief as a social experience influenced by people's cultures. A growing body of work focusing on grief work from an African perspective has emerged in the past few decades (Baloyi \& Makobe-Rabothata 2014; Canham 2020; Makgahlela et al. 2019; Nwoye 2000, 2005; Nwoye \& Nwoye 2012). These authors offer various critiques on the limitations and problematic nature of Euro-Western approaches to grief. Drawing on various African contexts, including Nigeria (West Africa), Kenya (East Africa) and South Africa, these scholars theorise about how varied communities respond to grief and then offer practical examples.

Gichinga (2007) points out that in many African contexts the grieving process involves the performing of various healing rituals. According to Jindra and Noret (eds. 2011), these rituals around death and burial have become key cultural practices in many African contexts. For example, in West African countries such as Ghana and Nigeria, bodies of the deceased are kept in the mortuaries for many weeks while the family is busy with preparations for burial in observance of various healing rituals (eds. Jindra \& Noret 2011). In some instances, these preparations can take months, especially if 1.See https://www.gov.za/covid-19/individuals-and-households/travel-coronaviruscovid-19. 
the deceased is a highly respected member of the community or belongs to the royal family (De Witte 2003). Thus, a delay in burying someone in West Africa is not a sign of weakness but, rather, a sign of prestige (eds. Jindra \& Noret 2011). However, the burial delays have economic implications for the family as it is costly to keep the dead body in a mortuary for a long period. Nevertheless, because of the cultural practices around the burial, many are willing to bear these costs.

In his extensive research on community involvement and intervention in grief work, Nwoye (2000, 2005; Nwoye \& Nwoye 2012) challenges the medicalisation of grief, engaging with grief work mainly in clinical spaces, and the general pathologisation of grief. Furthermore, Nwoye (2005) asserts that grief and mourning within an African context are a collective experience. It is therefore essential to highlight the importance of showing how an Afrocentric approach to grieving is necessary for us to make meaning of how African people respond to death and its implications for their lives.

According to Asante (2013), Afrocentricity is the recovering and reclaiming of who we are as a people, that is, the ways in which we engage with and respond to life experiences. It informs how we become who we are and the way we operate in the world. This would include our relationship with death, our grieving processes and how we mourn. During the time of colonial oppression and subjugation, many Africans relied on their spiritual selves/beliefs to survive. Spirituality has served as a critical instrument in assisting African people to survive the atrocities that they faced at the hands of their colonisers. In his discussion on the link between Afrocentricity and spirituality, Mazama (2002) calls for the need to seriously consider the role of spirituality as an integral part of how Africans make meaning of their world and how they connect with those who have passed (ancestors), and those who are still to come (the unborn). The past, present and future are viewed as being intertwined and forming the lived reality of many African people. This is in line with Baloyi and MakobeRabothata's (2014) assertion that:

$[F]$ rom an African perspective death is a natural transition from the visible to the invisible spiritual ontology where the spirit, the essence of the person, is not destroyed but moves to live in the spirit ancestors' realm of the dead. (p. 232)

The connection between the spirit world and the world of the living happens through the various rituals and ceremonies, including the burial ceremonies. Many African societies cope with grief around the loss of a loved one through these burial rituals and ceremonies.

It is this relationship between grief and spirituality that has attracted theologians to formulate a 'theology of grief'. This theology was meant to assist the practitioners of faith - in the form of pastors, chaplains, counsellors, elders and deacons - in how to address grief when it arises among their followers. However, in much the same way as the psychological perspectives on grief, these theologies were crafted by Western theologians and concentrated extensively on individual healing (Brueggemann 1977; Garrett 2008; Mitchell 1983). Such theologies addressed the use of biblical texts in the moment of grief (Brueggemann 1977) and the absence or presence of God during grief (Garrett 2008), leaving gaps in what we call 'collective grieving' in this article. Since then, voices have emerged in Africa calling for a relevant theology of grief. A theology that should be able to recognise the communal life in Africa. Mashau (2019), a South African theologian, calls it a 'theology of ubuntology', which is drawn from the African philosophy of Ubuntu. Ugandan Catholic priest and theologian, Emmanuel Katongole (2017), speaks of the theology of grief in Africa, whereby mourners come together to wrestle with grief, rather than passively accepting it.

Thus, grieving in Africa from both psychological and theological perspectives is not individualised but communal. Drawing on African philosophy, Nwoye (2005:148) defines African grief work as the patterned ways invented in traditional communities for the successful healing of the psychological wounds and pain of bereaved persons'. The COVID-19 pandemic flipped the script on how these 'invented patterned ways' of burying loved ones and the rituals that accompany them are conducted in South Africa. The hard lockdown and its regulations, as discussed previously, prevented people from being able to mourn collectively or hold night vigils to spend the night 'in the company' of the deceased. As Canham (2020:7) argues, 'COVID-19 has disrupted community and ritual. In its place, is an incredible loneliness where custom is replaced by regulation'. These disrupted rituals are crucial for people in various communities as they assist with their grieving processes. As indicated by Martin et al. (2013):

$[T]$ he complex interactions between the physically present earthbound mourners and deceased's body and soul, and a metaphysical-spiritual realm of deceased elders, familial guardians, and significant clan figures; and competing pressures of traditional culturally influenced mourning rituals and religioChristian burial ceremonies. (p. 46)

Are important interrelated aspects of death. The coronavirus disease 2019 regulations restrict the viewing of the dead body of a person who died from COVID-19, which creates complications when it comes to performing necessary burial rites. This is in line with the observation by Martin et al. (2013):

African bereavement rituals render 'death' a broadly dialectical process of shepherding the deceased's soul through a series of embodied rituals performed on or involving the bodies of both the deceased and the bereaved, and spiritual rituals which steward the deceased's soul to an ancestral-spiritual realm. Both sets of rituals are integral to attaining closure for the deceased and the bereaved. (p. 46)

According to Makgahlela et al. (2019):

$[B]$ ereavement rituals can be described as a set of culturally patterned behaviors or activities in which the bereaved engages for the purpose of symbolically expressing certain feelings and thoughts during mourning. (p. 1) 
The rituals aim at assisting mourners to cope with their loss and grief. In his theorising on the need for an African-centred grief therapy and response to death, Nwoye (2000) calls for the adoption of African Grief Therapy (AGT), which takes seriously the ways in which African people respond to loss. Nwoye (2000:60) suggests various structures/processes be followed as part of the grieving process:

1. The biological (where attention is directed at the physical health or well-being of the bereaved, with the intention to promote the bereaved's physical recovery from the 'blow' emanating from the loss).

2. The emotional (where healing is effected through the community's solidarity expressed in crying with the bereaved, thereby sending them the message - through both digital and analogic communication - that the bereaved are not alone in their loss).

3. The social (effected through the provision of both emotional and instrumental social support to reassure the bereaved and to protect them from suffering the full impact of the loss).

The above processes offer healing at multidimensional levels following the loss of a loved one. However, with the advent of COVID-19, it became difficult for communities to show solidarity with one another after the death of loved ones. Social interaction was limited, which might also have contributed to the prolonging of the process of bereavement. The process of showing solidarity with the bereaved is aimed at ensuring that people have support and a space to mourn with both family members and the community at their side, since the loss affects not only the family but society at large. The absence (of the departed person) would be felt not only by the immediate family members, but the entire community, as people do not exist in isolation but function as part of a whole. This is articulated further by Nwoye (2000), who argues that:

$[O]$ ur people have the conviction that when people participate in honouring or making well the exit and funeral ceremony of others they pave a big way for being equally honoured by those who survive their own exit. (p. 66)

Anecdotal evidence shows that even during the height of the COVID-19 pandemic, people insisted on attending funerals because they believed that it is important to do so, as they would want others to follow all the rituals for them. For many African people, the process of grieving and mourning the death of a loved one is also perceived as a political act wherein there is an insistence on acknowledging the life, memory and dignity of the departed (Canham 2020). For a people whose humanity has been negated for such a long time, there is a need to create avenues that allow for the dignified embracing of a life, whether dead or alive, and African rituals allow for this.

\section{Embodying grief as a psycho- theological response}

The comportments, postures, and accoutrements of the deceased's body are only given meaning in interaction with the corporeal configurations of the bereaved. This includes acts of slaughtering cattle, all-night vigils, communal wailing, and washing the deceased's body. Through those embodied acts the bereaved are systemically integrated into the bereavement process. (Martin et al. 2013:47)

In their study focusing on embodiment, Martin et al. (2013) refer to the importance of taking issues of body politics seriously. In many African cultures, the body of the deceased is an intricate part of the mourning and grieving process - the body must be seen by family members for them to have closure. This point is also highlighted by a reverend of the United Methodist Church in Zimbabwe, when reflecting on the experiences of some of her congregants (Kumuterera 2020):

Bodies were taken from the funeral parlour straight to the graveyard, not the church norm - no body viewing, no gathering at the family house. It was very traumatic. People faced stigma. They were depressed and pained. (p. 1)

For both the church and the family, the viewing of the dead body is part of the burial process, a process without which people struggle to let go and accept that their loved one has truly gone.

According to De Witte (2003), in African countries like Ghana, the body of the deceased is displayed in a decorated room for public viewing, whereas in South Africa, it is only family members and close friends who are free to view the body in a coffin. For example, among the Bapedi people in Limpopo, South Africa, this happens in two settings. The first is at the home of the deceased during the first funeral service or prior to the service. The second is when the actual burial at the cemetery is about to take place, when only very close family members and pastors are allowed to view the body of the deceased. In both instances, the mourners are given an opportunity to view the body of the deceased for the last time before he or she is finally laid to rest. Non-relatives would usually choose not to view the body of the deceased out of respect for the family (Bailey \& Walter 2016). The practice of viewing the dead body is part of the healing and coping mechanisms, as this helps the mourners to accept that the deceased has indeed passed away.

The importance of the deceased body's forming part of the burial rituals is one of the reasons African migrants insist on burying their loved ones in their home countries (Kgatle 2020a). For the same reason, they see the need to repatriate the body of their dead loved one to complete the grieving process during burial. Fontein (2009), in Kgatle (2020a), explains:

The process of bringing human bodies back [home] is done to bring back the spirit of the dead person back to his or her root and ensure that it rests in the right place. (p. 14)

Failure to bury the body in the home country might result in some misfortune for the remaining members of the family. The repatriation process happens not only in the context of migration around the continent, but also in South Africa, in what we term 'internal migration', where the bodies of the 
deceased are moved from one province to another to ensure that they are buried at home. Repatriation processes can be costly, but many families are willing to incur the costs as they deem it important to bury their loved ones at home, according to their various cultural practices. In some instances, the interprovincial migration is as costly as the continental because the distance is almost the same or even longer. Moving a dead body from Cape Town (South Africa) to Polokwane (South Africa) might cost just as much as moving a dead body from Polokwane (South Africa) to Harare (Zimbabwe), notwithstanding border costs.

The embodying manifestation of grief refers to the actual dead body and what it means to the bereaved; in addition, we also need to acknowledge how the bereaved manifests his or her grief. The coronavirus disease 2019 has caused many people to lose multiple loved ones in a short space of time, and the resulting regulations have adversely affected how pain, grief and loss are handled by the bereaved. According to Pearce and Komaromy (2020):

$[U]$ nderstanding grief as an embodied experience can enable the development of grief theories that better capture the complex negotiation between the psychological processes of grief and the materiality of bodies. (p. 1)

We need to acknowledge that grief happens at the physical, cultural, psychological and spiritual level. It is therefore pertinent to take seriously how all these dimensions intersect and influence the mourning and healing process of the bereaved. Canham (2020:5) reminds us: 'We (need to) see mourning as a humanizing pathway ... Through comforting those who grieve, we come to face our own vulnerabilities and incomplete mourning'. As we further reflect on the process of incomplete mourning, we ask: What happens to the many people who had to bury their loved ones without seeing their bodies one last time? How are the wounds to heal when the process of viewing the body - which acts to salve the pain - is not allowed because of the pandemic? These are critical questions to reflect on as we reconfigure life in general, going forward, and reimagine burial processes more specifically.

\section{Conclusion}

This article offered a psycho-theological interrogation of the grieving processes during a pandemic. We have examined the ways in which grief is understood and manifested in many African societies. Drawing from an Afrocentric perspective, we highlighted the challenges of understanding grief only from an individualistic perspective. We explored the ways in which COVID-19 negatively affected burial ritual practices of people and the possible longer-term negative impact thereof. We conclude by suggesting communal grieving as opposed to individualised forms of grief. Furthermore, we argue that for total healing to take place, the viewing of the deceased body (which offers people closure) should become part of the grieving process. Incorporating the body of the deceased in the grieving ritual is essential and will not necessarily perpetuate COVID-19; rather, it is an important way for families to cope with the challenges of death and burial during a pandemic. We therefore need to find ways of allowing people to follow and practise their burial rituals while maintaining the safety protocols of COVID-19.

\section{Acknowledgements}

The authors would like to thank the Department of Christian Spirituality, Church History and Missiology for the support provided in conducting this research.

\section{Competing interests}

The authors declare that they have no financial or personal relationships that may have inappropriately influenced them in writing this article.

\section{Authors' contributions}

M.S.K. contributed to the theological part and P.S. contributed to the psychological part of the article.

\section{Ethical considerations}

The ethical clearance was issued by the University of South Africa, College of Human Sciences Research Ethics Review Committee 2019-CHS-90343018-Dept.

\section{Funding information}

This research received no specific grant from any funding agency in the public, commercial or not-for-profit sectors.

\section{Data availability}

Data sharing is not applicable to this article as no new data were created or analysed in this study.

\section{Disclaimer}

The views and opinions expressed in this article are those of the authors and do not necessarily reflect the official policy or position of any affiliated agency of the authors.

\section{References}

Asante, M.K., 2013, Africentricity: Imagination and action, Multiversity Citizens International, Penang.

Bailey, T. \& Walter, T., 2016, 'Funerals against death', Mortality 21(2), 149-166. https://doi.org/10.1080/13576275.2015.1071344

Baloyi, L. \& Makobe-Rabothata, M., 2014, 'The African conception of death: A cultural implication', in L.T.B. Jackson, D. Meiring, F.J.R. Van de Vijver, E.S. Idemoudia \& W.K. Gabrenya Jr. (eds.), Toward sustainable development through nurturing diversity: Proceedings from the 21st International congress of the Internationa association for cross-cultural psychology, viewed 20 June 2018, from https:// scholarworks.gvsu.edu/iaccp_papers/119/.

Banerjee, I., Robinson, J., Sathian, B. \& Van Teijlingen, E.R., 2020, 'South Africa and its COVID-19 prohibition predilection', Nepal Journal of Epidemiology 10(3), 874 https://doi.org/10.3126/nje.v10i3.31543

Brueggemann, W., 1977, 'The formfulness of grief', Interpretation 31(3), 263-275. https://doi.org/10.1177/002096437703100304

Canham, H., 2020, 'Black death and mourning as pandemic', Journal of Black Studies 52(3), 296-309. https://doi.org/10.1177/0021934720981843 
De Witte, M., 2003, 'Money and death: Funeral business in Asante, Ghana', Journal of the International African Institute 73(4), 531-559. https://doi.org/10.3366/ afr.2003.73.4.531

Dodds, K., Broto, V.C., Detterbeck, K., Jones, M., Mamadouh, V., Ramutsindela, M. et al., 2020, 'The COVID-19 pandemic: Territorial, political and governance dimensions of the crisis', Territory, Politics, Governance 8(3), 289-298. https://doi. dimensions of the crisis', Territory, Politics,
org/10.1080/21622671.2020.1771022

Du Toit, P., 2020, South Africa beyond Covid-19: Trends, change and recovery, Jonathan Ball, Johannesburg.

Fontein, J., 2009, 'The politics of the dead: Living heritage, bones and commemoration in Zimbabwe', ASA Online 1(2), 1-27, viewed n.d., from https://www.theasa.org/ publications/asaonline/articles/asaonline_0102.shtml.

Garrett, G., 2008, Stories from the edge: A theology of grief, Westminster John Knox Press, Louisville, KY.

Gichinga, E., 2007, Counselling in the African context: A counselling guide, Africanbib, Lawrence, KS.

Jindra, M. \& Noret, J. (eds.), 2011, Funerals in Africa: Explorations of a social phenomenon, Berghahn Books, New York, NY.

Katongole, E., 2017, Born from lament, Wm. B. Eerdmans Publishing, Grand Rapids, MI.

Kenworthy, D. \& Kirkham, M., 2011, Midwives coping with loss and grief: Stillbirth, professional and personal losses, Radcliffe Publishing, Bristol.

Kessler, D., 2019, Finding meaning: The sixth stage of grief, Simon and Schuster, New York, NY.

Kgatle, M.S., 2020a, 'Dealing with the cultural and financial challenges during death of a loved one and repatriation of the remains: A mission to the wounded', HTS Theological Studies 76(4), a5970. https://doi.org/10.4102/hts.v76i4.5970

Kgatle, M.S., 2020b, 'Religious live-streaming in response to coronavirus disease 2019 pandemic and the subsequent lockdown in South Africa', Verbum et Ecclesia 41(1), a2120. https://doi.org/10.4102/ve.v41i1.2120

Kotzé, E., Els, L. \& Rajuili-Masilo, N., 2012, “'Women ... mourn and men carry on": African women storying mourning practices: A South African example', Death Studies 36(8), 742-766. https://doi.org/10.1080/07481187.2011.604463

Kübler-Ross, E., 1969, On death and dying, Springer, New York, NY.

Kübler-Ross, E. \& Kessler, D., 2005, On grief and grieving: Finding the meaning of grief through the five stages of loss, Simon and Schuster, New York, NY.

Kumar, S.M., 2005, Grieving mindfully: A compassionate and spiritual guide to coping with loss, New Harbinger Publications, Oakland, CA.

Kumuterera, C., 2020, Pastors reveal emotional toll of COVID-19, viewed 09 March 2021, from Pastors reveal emotional toll of COVID-19 | United Methodist News Service (umnews.org)

Letsosa, R., 2010, 'Liturgical aspects of funeral services in reformed churches of African origin', Verbum et Ecclesia 31(1), a361. https://doi.org/10.4102/ve.v31i1.361

Lukhele, F., 2016, 'Tears of the rainbow: Mourning in South African culture', Critical Arts 30(1), 31-44. https://doi.org/10.1080/02560046.2016.1164383

Makgahlela, M., Sodi, T., Nkoana, S. \& Mokwena, J., 2019, 'Bereavement rituals and their related psychosocial functions in a Northern Sotho community of South Africa', Death Studies 45(2), 91-100. https://doi.org/10.1080/07481187.2019.16 16852

Martin, J., Van Wijk, C., Hans-Arendse, C. \& Makhaba, L., 2013, “"Missing in action”: The significance of bodies in African bereavement rituals', Psychology in Society $44,42-63$.
Mashau, T.D., 2019, 'Foreigners go home! Re-imagining ubuntology and the agency of faith communities in addressing the migration crisis in the City of Tshwane', HTS Theological Studies 75(4), a5595. https://doi.org/10.4102/hts.v75i4.5595

Mazama, M.A, 2002 'Afrocentricity and African spirituality', Journal of Black Studies 33(2), 218-234. https://doi.org/10.1177/002193402237226

Mhlongo, N., 2007, After tears, Kwela Books, Johannesburg.

Mitchell, K.R., 1983, All our losses, all our griefs: Resources for pastoral care, Westminster John Knox Press, Louisville, KY.

Nwoye, A., 2000, 'Sources of gain in African grief therapy (AGT)', Journal of Family Psychotherapy 11(1), 59-72. https://doi.org/10.1300/J085v11n01_04

Nwoye, A., 2005, 'Memory healing processes and community intervention in grie work in Africa', Australian and New Zealand Journal of Family Therapy 26(3), 147-154. https://doi.org/10.1002/j.1467-8438.2005.tb00662.x

Nwoye, A. \& Nwoye, C.M.A., 2012, 'Memory and narrative healing processes in grie work in Africa: Reflections on promotion of re-anchoring', Journal of Family Psychotherapy 23(2), 138-158. https://doi.org/10.1080/08975353.2012.679904

Pearce, C. \& Komaromy, C., 2020, 'Recovering the body in grief: Physical absence and embodied presence', Health 1-18. https://doi.org/10.1177/1363459320931914

Posel, D., 2007, 'A matter of life and death', in L. McGregor \& S. Nuttall (eds.), At risk: Writing on and over the edge of South Africa, pp. 48-76, Jonathan Ball, Johannesburg.

Rogerson, C.M. \& Rogerson, J.M., 2020, 'COVID-19 tourism impacts in South Africa: Government and industry responses', GeoJournal of Tourism and Geosites 31(3), 1083-1091. https://doi.org/10.30892/gtg.31321-544

Semenya, D.K., 2013, 'Burial society versus the church in the black society of South Africa: A pastoral response', Verbum et Ecclesia 34(1), 55-63. https://doi. org/10.4102/ve.v34i1.698

Setsiba, T.H.S., 2012, 'Mourning rituals and practices in contemporary South African townships: A phenomenological study', Doctoral dissertation, University of Zululand.

South African Government, 2021, 'Travel - Coronavirus COVID-19', viewed 01 March 2021 from https://www.gov.za/covid-19/individuals-and-households/travel-coronaviruscovid-19.

Stroebe, M.S., Stroebe, W. \& Hansson, R.O. (eds.), 1993, Handbook of bereavement Theory, research, and intervention, Cambridge University Press, Cambridge.

Sutcliffe, P., Tufnell, G. \& Cornish, U. (eds.), 1998, Working with the dying and the bereaved: Systemic approaches to therapeutic work, Macmillan, London.

Walter, T., 2007, 'Modern grief, postmodern grief', International Review of Sociology Revue Internationale de Sociologie 17(1), 123-134. https://doi.org/10.1080/ 03906700601129798

Western Cape Government, 2020, Provincial guide to cultural and religious practices and observances in managing COVID-19 fatalities in the Western Cape, viewed 02 June 2020, from https://coronavirus.westerncape.gov.za/files/atoms/files/Provincial\%20 guide $\% 20$ for $\% 2$ FFunerals $\% 20-\% 2001 \% 2006 \% 202020 \_$ABF.pdf.

World Health Organization, 2020, Infection prevention and control for the safe management of a dead body in the context of COVID-19, viewed 20 September 2020, from https://www.who.int/publications/i/item/infection-prevention-andcontrol-for-the-safe-management-of-a-dead-body-in-the-context-of-covid-19interim-guidance.

Zanker, F.L. \& Moyo, K., 2020, 'The corona virus and migration governance in South Africa: Business as usual?', Africa Spectrum 55(1), 100-112. https://doi. org/10.1177/0002039720925826 